Supplement of Atmos. Chem. Phys., 19, 13175-13188, 2019

https://doi.org/10.5194/acp-19-13175-2019-supplement

(c) Author(s) 2019. This work is distributed under

the Creative Commons Attribution 4.0 License.

(c) (i)

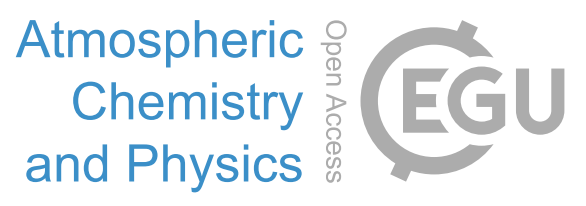

Supplement of

\title{
Role of black carbon mass size distribution in the direct aerosol radiative forcing
}

\section{Gang Zhao et al.}

Correspondence to: Chunsheng Zhao (zcs@pku.edu.cn)

The copyright of individual parts of the supplement might differ from the CC BY 4.0 License. 


\section{Correcting the AE51}

Fig. S1 showed the results of the loading effect corrections. At the beginning of the field experiment, parallel measurement of $\sigma_{a b s}$ by AE51 and AE33 was conducted. Before corrections, the measured $\sigma_{a b s}$ by AE51 and AE33 showed significant discrepancy with each other with slope and $\mathrm{R}^{2}$ equaling 0.55 and 0.83 . However, the $\sigma_{a b s}$ measured by AE33 and by AE51 with loading effects corrections showed good consistency in trends and magnitudes with slope and $\mathrm{R}^{2}$ of 0.98 and 0.94 respectively. These results demonstrated that the loading effects corrections of $\sigma_{a b s}$ from AE51 were essential and the value of $\sigma_{a b s}$ from AE33 can be used as a reference for the measured size-resolved $\sigma_{a b s}$.

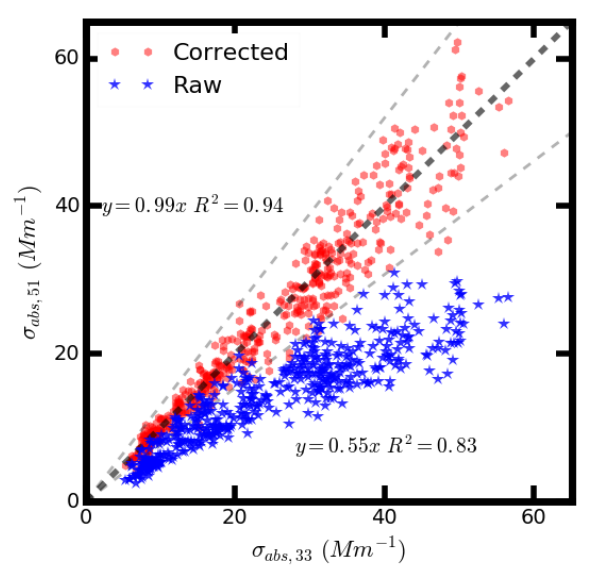

Figure S1. Comparison between the $\sigma_{a b s}$ measured by AE51 and AE33. The blue stars and the red dots represents uncorrected and corrected $\sigma_{a b s}$ of AE51 respectively.

\section{Time correction}

There were two reasons that can lead to this difference: firstly, the time of the AE51 system and the computer that controls the CPC cannot be synchronized all the time; secondly, there existed a difference in the plumbing delay time, which was the time required for particles to flow through the tubing interconnecting the DMA and CPC or AE51, and arrive at the detector. To sum up, the synchronization of the time reported by CPC and AE51 was necessary. 
Time synchronization was conducted by measuring the time lag of the signal pulses from the DMA to CPC and AE51. The signal pulses resulted from the sudden change of the aerosol diameter scanned by DMA. Details of the method were shown below. In fig. S2, the black solid line gave the time series of the measured $\sigma_{a b s}$ by AE51. The dotted lines gave the time series of the aerosol number counted by CPC of (a) unsynchronized and (b) synchronized. In the beginning, the scan diameter of the DMA was set to be less than 13nm and the values measured by AE51 and CPC are nearly zero. The values get a step jump and a step drop when changing the scan diameter up to about 200nm and down back to less than $13 \mathrm{~nm}$. About 15s later, these procedures were conducted once again. From fig. S2(a) and fig. S2(b), the lag time of the AE51 and CPC were determined to be 20s by matching the pulse signals.

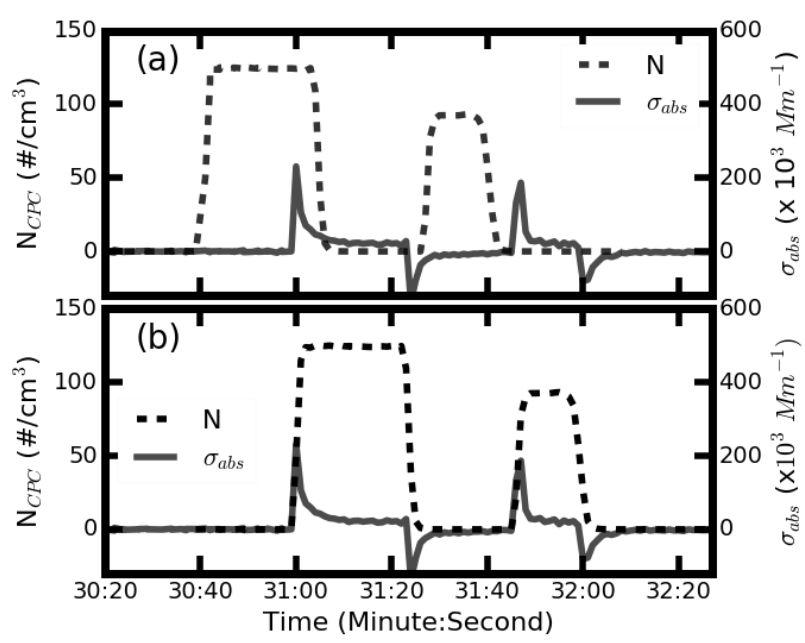

Figure S2. An example of time synchronization processing, (a) for unsynchronized and (b) for synchronized. The dotted line is the aerosol number concentration time series counted by CPC. The black solid line is the $\sigma_{a b s}$ measured by AE51.

3. Time series diagram of scanned aerosol diameters, measured $m_{B C}$ and the aerosol number concentrations 


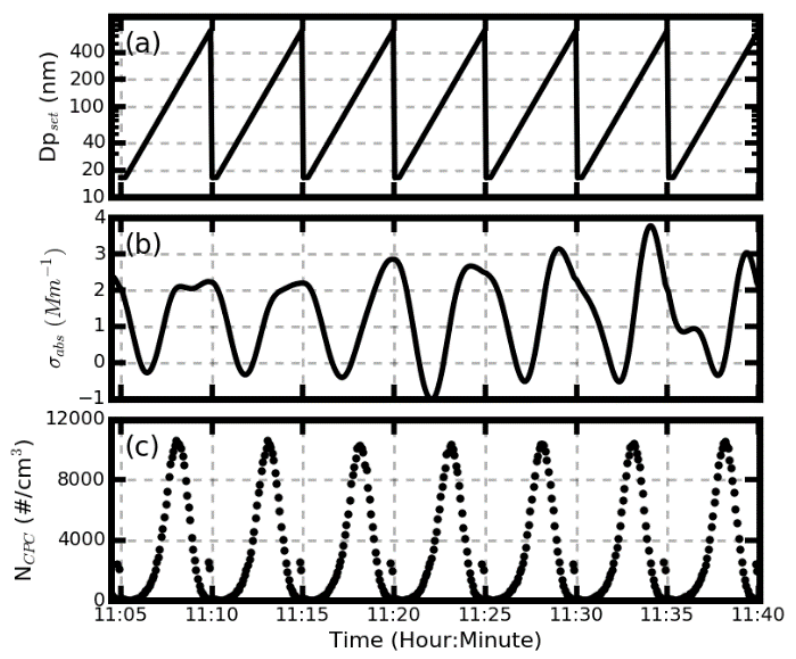

Figure S3 (a) the diameters of the aerosols that pass through the DMA (b) The $\sigma_{a b s}$ values measured by AE51, (c) the aerosol number concentrations measured by CPC.

\section{Validation of the multiple charging corrections}
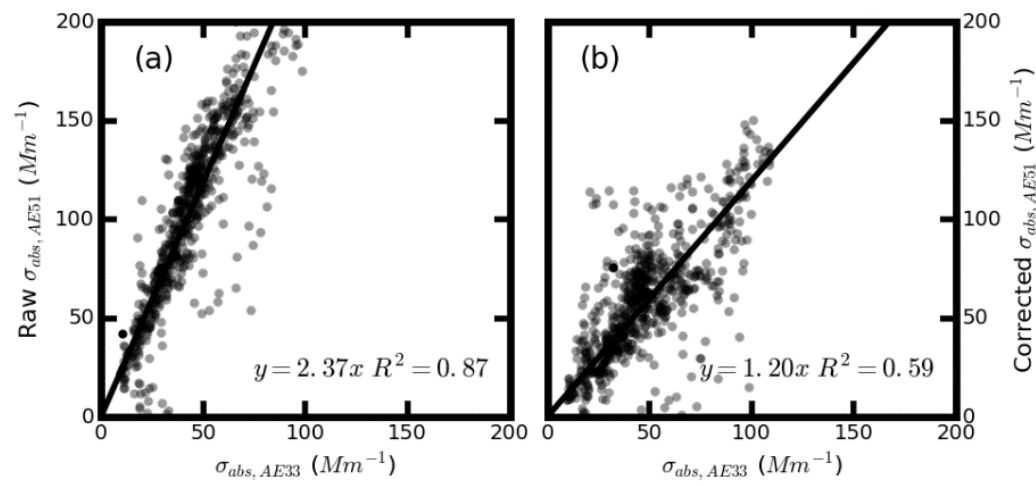

Figure S4. $\sigma_{a b s}$ measured by AE33 versus $\sigma_{a b s}$ integrated from AE51 of (a) uncorrected size-resolved $\sigma_{a b s},(\mathrm{~b})$ multiple-charging corrected size-resolved $\sigma_{a b s}$.

\section{Estimate the DARF}

DARF is defined as the difference between radiative flux at the TOA under present aerosol conditions and aerosol-free conditions:

$$
\operatorname{DARF}=\left(f_{a} \downarrow-f_{a} \uparrow\right)-\left(f_{m} \downarrow-f_{m} \uparrow\right)
$$

Where $f_{a} \downarrow$ is the downward radiative irradiance and $f_{a} \uparrow$ is the outward radiative irradiance under given aerosol distributions; $\left(f_{a} \downarrow-f_{a} \uparrow\right)$ is the downward radiative irradiance flux with given aerosol distributions and $\left(f_{m} \downarrow-f_{m} \uparrow\right)$ is the radiative irradiance flux under aerosol free conditions.

Input data for the SBDART are listed below. Vertical profiles of the aerosol optical properties, 
which include the aerosol extinction coefficient $\left(\sigma_{\text {ext }}\right)$, aerosol single scattering albedo (SSA) and g with a height resolution of $50 \mathrm{~m}$, come from the parameterization of aerosol vertical distributions (as shown in fig. S4 and the next paragraph) and the results of the Mie model. Atmospheric gas and meteorological parameter profiles come from the mean results of the radiosonde observations at the Meteorological Bureau of Beijing $\left(39^{\circ} 48^{\prime} \mathrm{N}, 116^{\circ} 28^{\prime} \mathrm{E}\right.$ ), which include profiles for water vapor, pressure and temperature during the spring. Surface albedo values are obtained from the Moderate Resolution Imaging Spectroradiometer (MODIS) V005 Climate Modeling Grid (CMG) Albedo Product (MCD43C3) during March, 2017 of Beijing, where the field campaign is conducted. The remaining input data for the SBDART are set to their default values.

\subsection{Parameterization of the aerosol vertical distribution}

Liu et al. (2009) studied vertical profiles of aerosol total number concentration (Na) with aircraft measurements, and derived a parameterized vertical distribution. In this scheme, $\mathrm{Na}$ is constant in the mixed layer, with a transition layer where it linearly decreases and an exponential decrease of $\mathrm{Na}$ above the transition layer. The same parameterized scheme proposed by Liu et al. (2009) is adopted by this study as shown in fig. S4 (b). Both the study of Liu et al. (2009) and Ferrero et al. (2010) manifest that the dry aerosol PNSD in the mixed layer varies little. The shape of the dry aerosol PNSD is assumed constant with height, which means that aerosol PNSD at different heights divided by Na give the same normalized PNSD.

As for the BC vertical distribution, Ferrero et al. (2011) and Ran et al. (2016) demonstrate that BC mass concentration in the mixed layer remains relatively constant and decreases sharply above the mixed layer. According to this, the parameterization scheme of $\mathrm{BC}$ vertical distribution is assumed to be the same as that of aerosol. The shape of the size-resolved BC mass concentration distribution is also assumed to be the same as that at the surface. 


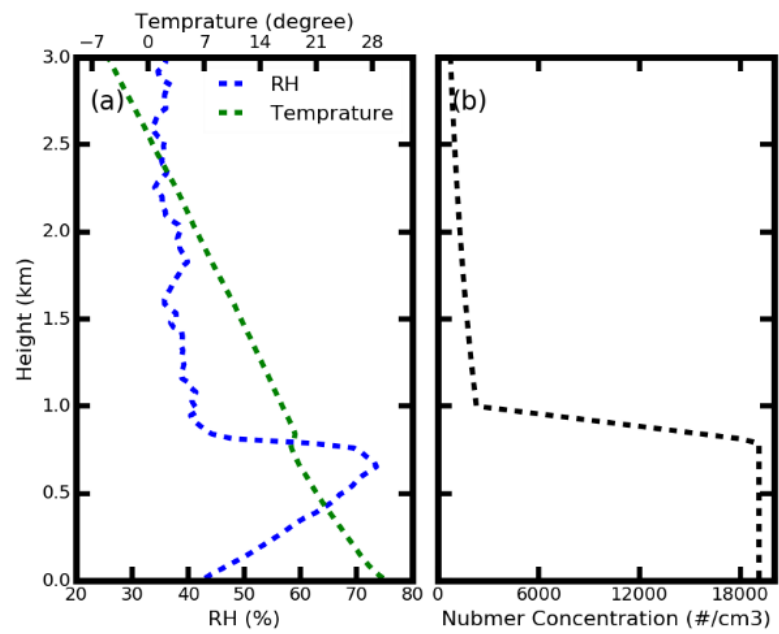

Figure S5. The mean RH, temperature, and aerosol number concentration profiles.

\subsection{Calculate the aerosol optical profiles under the given $\mathrm{RH}$ profile}

With the vertical distribution of aerosol PNSD and BCMSD, the aerosol optical properties at a given RH profile can be calculated by using the Mie scattering model and $\kappa$-Köhler theory (Petters and Kreidenweis, 2007).

The aerosol hygroscopic growth is taken into consideration when calculate the aerosol optical properties under the given RH. The $\kappa-$ Köhler theory (Petters and Kreidenweis, 2007) is widely used to describe the hygroscopic growth of aerosol particles by using a single aerosol hygroscopic growth parameter $(\kappa)$ and the $\kappa-$ Köhler equation, which is shown as

$$
\frac{R H}{100}=\frac{g f^{3}-1}{g f^{3}-(1-\kappa)} \cdot \exp \left(\frac{4 \sigma_{s / a} M_{w a t e r}}{R \cdot T \cdot D_{d} \cdot g f \cdot \rho_{w}}\right),
$$

where $D_{d}$ is the dry particle diameter; $\mathrm{gf}(\mathrm{RH})$ is the aerosol growth factor, which is defined as the ratio of the aerosol diameter at a given $\mathrm{RH}$ and the dry aerosol diameter $\left(D_{R H} / D_{d}\right)$; $\mathrm{T}$ is the temperature; $\sigma_{\mathrm{s} / \mathrm{a}}$ is the surface tension of the solution; R is the universal gas constant and $\rho_{\mathrm{w}}$ is the density of water. The aerosol hygroscopic growth parameter $\kappa$ can be further used to investigate the influence of aerosol hygroscopic growth on aerosol optical properties (Tao et al., 2014;Kuang et al., 2015; Zhao et al., 2017) and aerosol liquids water contents (Bian et al., 2014).

The $\kappa-$ Köhler theory and the Mie scattering model are combined to calculate aerosol extinction coefficient, aerosol single scattering albedo and aerosol asymmetry factor under different $\mathrm{RH}$ conditions. The measured mean $\kappa$, which is derived from the humidified nephelometer system (Kuang 
et al., 2017), is used to account for aerosol hygroscopic growth. For each RH value, the gf can be calculated based on equation (1). The corresponding ambient aerosol PNSD at a given RH can be determined. The refractive index $(\widetilde{m})$, which accounts for water content in the particle, is derived as a volume mixture between the dry aerosol and water (Wex et al., 2002):

$$
\widetilde{m}=f_{V, d r y} \widetilde{m}_{\text {aero,dry }}+\left(1-f_{V, d r y}\right) \widetilde{m}_{\text {water }}
$$

where $f_{v, d r y}$ is the ratio of the dry aerosol volume to the total aerosol volume under a given $\mathrm{RH}$ condition; $\widetilde{m}_{a e r o, d r y}$ is the refractive index for dry ambient aerosols and $\widetilde{m}_{w a t e r}$, the refractive index of water, is $1.33+10^{-7} \mathrm{i}$. Then, the corresponding aerosol optical properties under the given $\mathrm{RH}$ and PNSD can also be calculated. Finally, the aerosol optical profiles can be calculated. Fig. S6 shows one of the calculated aerosol optical profiles.

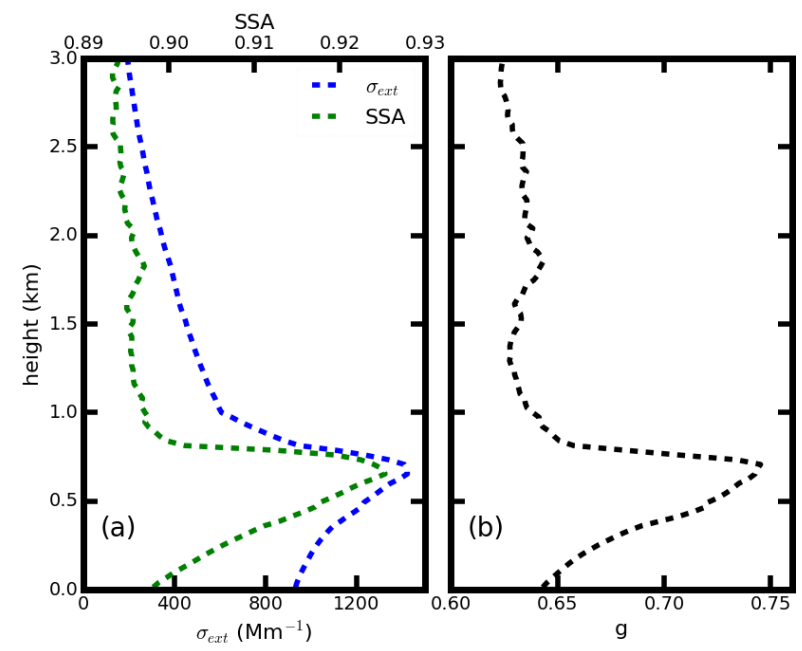

Figure S6. The calculated profiles of the aerosol extinction coefficient, aerosol single scattering albedo and the aerosol asymmetry factor.

\section{Relationship between the GSD, Dm and mBC}




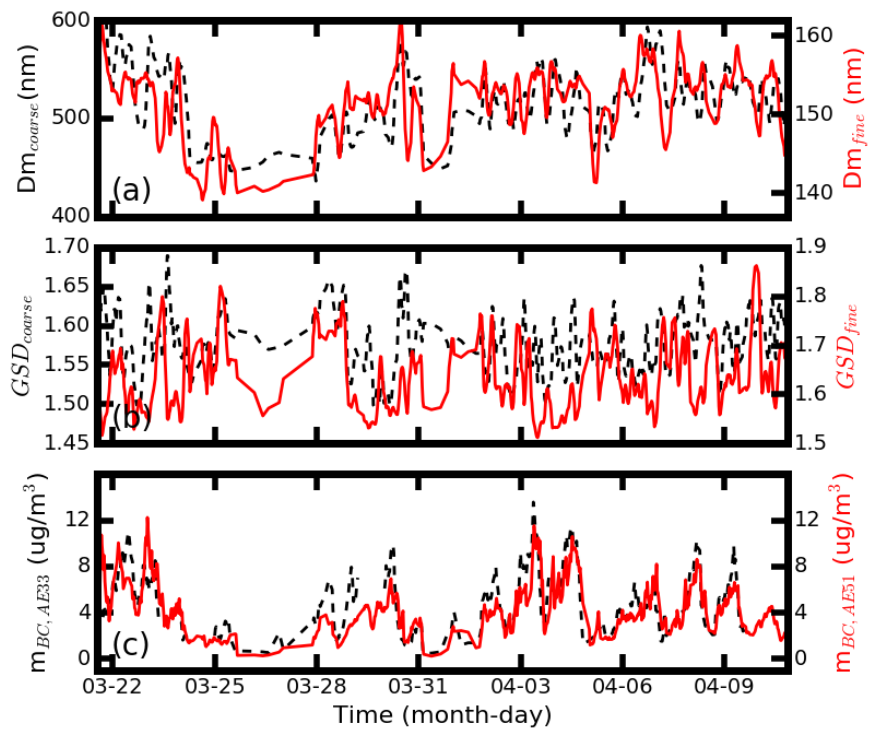

Figure S7. The (a) Dm and (b) GSD of the BCMSD at coarse mode (black) and fine mode (red); (c) measured $\mathrm{m}_{\mathrm{BC}}$ by $\mathrm{AE} 33$ (black) and measured $\mathrm{m}_{\mathrm{BC}}$ from integrated $\mathrm{m}_{\mathrm{BC}}$ of the BCMSD from AE51.

Bian, Y. X., Zhao, C. S., Ma, N., Chen, J., and Xu, W. Y.: A study of aerosol liquid water content based on hygroscopicity measurements at high relative humidity in the North China Plain, Atmospheric Chemistry and Physics, 14, 6417-6426, 10.5194/acp-14-6417-2014, 2014.

Ferrero, L., Perrone, M. G., Petraccone, S., Sangiorgi, G., Ferrini, B. S., Lo Porto, C., Lazzati, Z., Cocchi, D., Bruno, F., Greco, F., Riccio, A., and Bolzacchini, E.: Vertically-resolved particle size distribution within and above the mixing layer over the Milan metropolitan area, Atmospheric Chemistry and Physics, 10, 3915-3932, 2010.

Ferrero, L., Mocnik, G., Ferrini, B. S., Perrone, M. G., Sangiorgi, G., and Bolzacchini, E.: Vertical profiles of aerosol absorption coefficient from micro-Aethalometer data and Mie calculation over Milan, Science of the Total Environment, 409, 2824-2837, 2011.

Kuang, Y., Zhao, C. S., Tao, J. C., and Ma, N.: Diurnal variations of aerosol optical properties in the North China Plain and their influences on the estimates of direct aerosol radiative effect, Atmos. Chem. Phys., 15, 5761-5772, 10.5194/acp-15-5761-2015, 2015.

Kuang, Y., Zhao, C., Tao, J., Bian, Y., Ma, N., and Zhao, G.: A novel method for deriving the aerosol 
hygroscopicity parameter based only on measurements from a humidified nephelometer system, Atmos. Chem. Phys., 17, 6651-6662, 10.5194/acp-17-6651-2017, 2017.

Liu, P., Zhao, C., Zhang, Q., Deng, Z., Huang, M., Xincheng, M. A., and Tie, X.: Aircraft study of aerosol vertical distributions over Beijing and their optical properties, Tellus Series B-Chemical \& Physical Meteorology, 61, 756-767, 2009.

Petters, M. D., and Kreidenweis, S. M.: A single parameter representation of hygroscopic growth and cloud condensation nucleus activity, Atmos. Chem. Phys., 7, 1961-1971, 10.5194/acp-7-1961-2007, 2007.

Ran, L., Deng, Z., Xu, X., Yan, P., Lin, W., Wang, Y., Tian, P., Wang, P., Pan, W., and Lu, D.: Vertical profiles of black carbon measured by a micro-aethalometer in summer in the North China Plain, Atmospheric Chemistry and Physics, 16, 10441-10454, 10.5194/acp-16-10441-2016, 2016.

Tao, J. C., Zhao, C. S., Ma, N., and Liu, P. F.: The impact of aerosol hygroscopic growth on the single-scattering albedo and its application on the NO2 photolysis rate coefficient, Atmos. Chem. Phys., 14, 12055-12067, 10.5194/acp-14-12055-2014, 2014.

Wex, H., Neususs, C., Wendisch, M., Stratmann, F., Koziar, C., Keil, A., Wiedensohler, A., and Ebert, M.: Particle scattering, backscattering, and absorption coefficients: An in situ closure and sensitivity study, J Geophys Res-Atmos, 107, 10.1029/2000jd000234, 2002.

Zhao, G., Zhao, C., Kuang, Y., Tao, J., Tan, W., Bian, Y., Li, J., and Li, C.: Impact of aerosol hygroscopic growth on retrieving aerosol extinction coefficient profiles from elastic-backscatter lidar signals, Atmos. Chem. Phys. Discuss., 2017, 1-24, 10.5194/acp-2017-240, 2017. 